\title{
ПОДГОТОВКА К МЕЖДУНАРОДНОМУ ЭКЗАМЕНУ КАК ИНСТРУМЕНТ ФОРМИРОВАНИЯ ИНОЯЗЫЧНОЙ КОММУНИКАТИВНОЙ КОМПЕТЕНЦИИ СТУДЕНТА-НЕЛИНГВИСТА
}

\section{PREPARATION FOR INTERNATIONAL EXAMINATION AS MEANS OF FORMING TECHNICAL STUDENT'S COMMUNICATIVE COMPETENCE}

\section{Bernshteyn \\ M. Bernshteyn}

Summary: The article theoretically analyses the main factors influencing the formation of productive reading skills as a component of foreign language communicative competence. It gives the reasons for lack of skills to elicit information from technical and business texts by students - non-linguists. The article analyses the main problems of preparation for international Business English Vantage examination for students studying on Bachelor and Master Programs "International management". It is defined that for the development of the ability to understand the gist of the text it is necessary to include systematic teaching of unprepared reading in the classroom activities. Student's performance has to be based not only on special exercises, classroom practice and additional language material, but includes elements of time-management and regular expanding of professional vocabulary.

Keywords: meaning, text, BEC Vantage examination, reading techniques, algorithm of development.

\section{Введение}

И зменение конфигурации как всего миропорядка в целом, так и каждого языкового сообщества в отдельности, нашли отражение во многих сферах жизнедеятельности социума, в том числе, в образовательной сфере. Особенно сильное влияние это изменение оказало на характер и содержание обучения иностранным языкам в вузах нелингвистического профиля. Образовательная дисциплина «Иностранный язык» приобрела совершенно иной статус: из обычной дисциплины общегуманитарного блока в вузах неязыкового профиля «Иностранный язык» превратился в учебную дисциплину, овладение которой обеспечивает студентов умением иноязычного межкультурного общения как неотъемлемого компонента бизнес - образования. Российские студенты-бакалавры и магистры имеют возможность выехать за рубеж для продолжения образования по программам двойного диплома, осуществляемым на
Бернштейн Виктория Левоновна

К.n.н., дочент, Российская академия народного хозяйства и государственной службы при Президенте Российской Федерации (Москва)

v.bernstein@mail.ru

Бернштейн Мария Михайловна

К.э.н., дочент, Российская академия народного хозяйства и государственной службы при Президенте Российской Федерации (Москва) mmb@ibs-m.ru

Аннотация: В статье теоретически осмыслены основные факторы, влияющие на формирование умений продуктивного чтения как компонента иноязычной коммуникативной компетенции студента-нелингвиста. Проанализированы причины, тормозящие процесс понимания и извлечения информации из профессиональных текстов в целом, и частные проблемы подготовки к международным экзаменам по деловому английскому языку студентов и магистров специальности «Международный менеджмент», связанные с умением продуктивного чтения. Определено, что для формирования умения понять смысл прочитанного необходимо включить в аудиторную работу неязыковых вузов не только систематическое обучение неподготовленному чтению, основанное на специальных упражнениях и дополнительном языковом материале, но и целенаправленную работу над расширением профессионального словаря, долговременной памяти и умения управлять временем.

Ключевые слова: смысл, текст, экзамен ВЕС Vantage, техника чтения, алгоритм развития.

английском языке. В России открыты Магистерские Программы, например англоязычная магистерская программа «Международный менеджмент» [1], преподавание которых полностью осуществляется на английском языке российскими и зарубежными педагогами. Эта трансформация значительно повлияла на общую оценку качества молодого специалиста - выпускника неязыкового вуза: для того, чтоб быть востребованным и конкурентоспособным на современном рынке труда знание иностранного языка стало обязательным. Эта «обязательность» знания языка стала актуальной как для выпускников - бакалавров, так и для выпускников магистерских программ, получающих бизнес образование, как потенциальных работников и руководителей международных компаний, с том числе в зарубежных странах

Однако на практике в процессе обучения иностранным языкам в достаточной мере осуществляется развитие (общее, лингвистическое) студентов, и этим, в 
соответствии с концепциями образовательного процесса, его цель как будто достигается. Но при этом упускается из виду реализация коммуникативной цели обучения иностранным языкам, т.е. до какого уровня удалось сформировать иноязычную коммуникативную компетенцию студентов. Если владение студентами иноязычной коммуникативной компетенцией на профессиональном уровне не достигнуто, то можно утверждать, что развивающее обучение применительно к преподаванию иностранных языков неэффективно. Существует сверхзадача курса иностранных языков в неязыковом вузе: обеспечить практическое владение студентами иностранным языком как профессиональным умением» [2: 25].

\section{Продуктивное чтение как компонент коммуникативной компетеншии студента}

В качестве ведущей цели обучения иностранным языкам, обозначенной в Государственных образовательных стандартах, рассматривается развитие иноязычной коммуникативной компетенции в совокупности всех ее составляющих: речевой, языковой, социокультурной, компенсаторной и учебно-познавательной компетенций. То есть коммуникативная компетенция реально рассматривается как «функциональная языковая способность; выражение, интерпретация и обсуждение значения, включая взаимодействие между двумя или несколькими индивидами, или между одним индивидом и письменным или устным текстом [3: 272]. В формировании коммуникативной компетенции студента неязыкового вуза важнейшая роль принадлежит развитию умения читать иноязычные тексты, извлекать из них информацию и оперировать этой информацией в процессе собственного высказывания в ситуациях аутентичного общения. Не требует доказательства факт, что целью любого чтения является адекватное понимание прочитанного. Противоречием является то, что умение читать, по мнению многих преподавателей вуза, должно быть сформировано в школе, поэтому в стенах института его формированию не уделяется должного внимания.

В настоящее время умение продуктивного чтения стало не просто личной потребностью обучаемого, но и неким мерилом уровня знания делового английского языка: успешным залогом сдачи международного экзамена, например, Business English Cambridge. Без Сертификата международного уровня владения английским языком многие зарубежные университеты и бизнес школы не принимают иностранных, в том числе российских, студентов по Программам двойного диплома и на стажировку. Поэтому, и студенты магистратуры, обучающиеся по англоязычной программе «Международный Менеджмент» и студенты-бакалавры различных международных специальностей активно мотивированы к сда- че экзамена BEC Vantage, валидного на протяжении всей жизни и отражающего уровень знания Делового английского языка по международным стандартам.

Факт интереса студентов к международным экзаменам явился новым стимулом, привлекшим пристальное внимание преподавателей неязыковых вузов к путям развития умения продуктивного чтения как весомой составляющей иноязычной коммуникативной компетенции вообще и содержания международного экзамена в частности. В качестве учебного эксперимента некоторыми кафедрами было принято решение о введении подготовки к сдаче Международного экзамена в формате Business English Cambridge в учебный план студентов четвертого курса факультета «Международный бизнес и деловое администрирование» и введением этого экзамена в качестве итоговой аттестации студентов - бакалавров в ИБДА РАНХиГС с 2019 года. Эта инновация была справедливо встречена с осторожностью некоторыми преподавателями, по причине однотипности заданий и угрозы потери творческого начала и общего интереса на занятиях.

Экзамен ВЕС проводится с учетом языкового уровня студента и включает четыре составляющих соответственно четырем умениям: Reading (продолжительность 1 час), Writing (45 минут), Listening (40 минут), Speaking (14 минут). Процесс подготовки к указанному экзамену обострил имеющиеся «общие» проблемы в обучении студентов неязыковых вузов, а также выявил «специфические» проблемы, относящиеся к формату и содержанию экзамена ВЕС. В этой статье мы остановимся на проблемах, связанных с умением читать, как самому объемному разделу этого международного экзамена.

Общие проблемы обучения чтению студента-нелингвиста

Практика преподавания в стенах неязыкового вуза показывает, что у студентов систематически возникает трудность понимания прочитанного текста и, как следствие, невозможность этот текст не только аннотировать или реферировать, но часто даже сформулировать главную идею прочитанного. Этот факт подтверждает мысль о том, что процессы восприятия и понимания текста не протекают одновременно. Умение студентов читать неполноценно, а технические навыки чтения сформированы на недостаточном уровне. При таком состоянии умения читать процесс извлечения информации является затруднительной пословной дешифровкой текста, не дающей ни информативного, ни эмоционального удовольствия от прочитанного текста. Кроме того, большинство преподавателей наряду с другими трудностями, связанными с отсутствием понимания прочитанного, часто отмечают отсутствие умения прочитать незнакомое слово. 
И этому можно назвать несколько причин:

- неадекватность существующей в школе методики обучения технике чтения требованиям и целям обучения в вузе;

- недостаточная скорость чтения на иностранном языке: для обеспечения универсальных навыков чтения, его скорость должна быть приближена к скорости чтения на родном языке;

- отсутствие практики чтения незнакомых текстов в аудитории в вузе вообще, что лишает студента возможности получить от преподавателя рекомендации и алгоритм действий;

- отсутствие специальных заданий по чтению незнакомых текстов для выработки у студента навыков сопоставить, провести аналогии, догадаться о значении незнакомых слов по контексту;

- поверхностное понимание окружающих явлений и информации, ставшее массовым в современном обществе, неспособность увидеть суть происходящего.

Bсе вышеперечисленное приводит к тому, что студент механически читает без понимания смысла, который несет в себе текст. То есть, автор текста закодировал свою мысль в системе иностранного языка, а читающий этот текст студент должен понять смысл, раскодировав языковые средства иностранного языка, а это, как правило, является непосильной задачей для студента неязыкового вуза.

Следует отметить, что умение извлекать информацию из текста является комплексным умением. Обучаемый должен знать, что смысл текста не является суммой знаний отдельных слов, из которых он состоит, то есть понять текст не эквивалентно понять значения отдельных слов, даже если они выучены. Для полноценного умения извлекать информацию необходима комплексная подготовка, основанная на методической системе [4].

По мнению таких методистов и исследователей как Н.В. Барышников, обучение чтению в школе рационально строить на навыковой модели обучения читать, в которую включены технические навыки чтения, рецептивные лексические и грамматические навыки, умение антиципации, догадка, умение сокращать тексты за счет малосущественных деталей, навыки пользования и умение рационально использовать справочную литературу в процессе чтения [4: 76].

Рассмотрим некоторые эффективные пути, необходимые и возможные в условиях обучения в неязыковом вузе, которые скорректируют умения извлекать информацию при чтении. Основой работы в этом направлении является формирование технических навыков неподготовленного чтения, то есть улучшение техники чтения с применением специальных упражнений.

Одним из основных методов обучения чтению начинающих является метод целых слов, когда обучаемый учится читать слова, предварительно отработанные в устной речи, опираясь на связь между звуковым и графическим образом данного слова. Являясь отработанным и проверенным временем методом для начинающих, в дальнейшем он является тормозом в становлении универсальных навыков чтения. Торможение развития заключается в том, что обучаемый получает навык читать только знакомые хорошо отработанные слова и не получает навыка воспринимать печатный текст как некую графическую информацию, основанную на буквенно-звуковых связях. Именно поэтому продолжительная отработка в устной речи только языкового материала базового учебника и предложенного в нем текста, по сути, не развивает умение читать, а наоборот, тормозит развитие данного умения.

Улучшение техники чтения студента возможно лишь при условии включения широкого спектра дополнительных текстов, ориентированных на соответствие в тематике изучаемого языкового материала и общий уровень знания языка студентом в аудиторную работу. Следует отметить, что в аудитории дополнительной сложностью, с которой сталкивается преподаватель, является то, что студенты читают с разной скоростью и разными способами. Практика преподавания показывает, что в большинстве случаев, студенты настроены на то, что они должны понимать значение каждого слова, а это, в свою очередь, приводит к очень медленному темпу чтения текста и невозможности охватить смысл параграфа и текста в целом.

Задачей преподавателя вуза является научить всех студентов читать неподготовленные тексты, имея четкую последовательную установку: цель чтения текста, идея этого текста, его ключевая информация.

Оба вида чтения: экстенсивное (беглое, просмотровое, с целью найти определенную информацию в статье); и интенсивное (тщательное, детальное) - должны быть отражены в аудиторной работе преподавателя и студентов. Но особое место в работе должно занять экстенсивное чтение как новый вид учебной деятельности для большинства пришедших в вуз студентов.

Известны различные методические подходы к обучению читать [5: 263]. Мы считаем обязательными для студентов неязыковых факультетов следующие подходы:

- введение в тему предложенного студентам текста, предварительная работа, содержащая просматривание заголовка текста и отдельных языковых сложностей; 
- постановка одновременно одного четкого задания (определить ключевые слова в абзаце, или прочитать абзац/ параграф и сформулировать его главную идею, или найти в статье ответы на 1/2/3 поставленных преподавателем вопроса и т.д.).

- чтение текста в строго установленное время [6].

Данные задания, направленные на развитие скорости чтения, являются одновременно и базой для развития умения понять содержание прочитанного, выделить главную информацию и понять структуру текста.

Большое внимание преподавателя также должно быть обращено на развитие рецептивных лексических и грамматических навыков чтения, которые призваны развивать языковое чутье, определять значение новых слов по контексту, по содержащимся в них знакомым элементам. Умение антиципации, догадка, - также необходимо для умения извлечь информацию и может быть развито с помощью практики. Для развития данного умения применимы следующие упражнения: прочитать предложение и определить значение выделенного слова по контексту; дополнить предложения недостающими словами; написать свой вариант окончания текста и затем сравнить с оригиналом.

Для определения полноты понимания текста необходима постоянная проверка понимания прочитанного, которая может проводиться с помощью серии вопросов, проверяющих понимание студентом текста. Эту проверку понимания смыслов необходимо выстроить в следующей последовательности: понимание на уровне ключевого языкового материала; понимание на уровне главной идеи и значимой информации; понимание на уровне подтекста, если таковой имеется в данном тексте.

\section{Спешифические проблемы подготовки к выполнению раздела «Чтение» межАународного экзамена}

Подготовка к международному экзамену, как упоминалось выше, выявила некоторые специфические проблемы, которые включают, прежде всего, наличие у студента ряда специальных умений, таких как умение напряженно работать в ситуации строго ограниченного времени и грамотного его распределить. К этой сложности не были изначально готовы даже те, кто имеет отличные знания по иностранному языку. В разделе Reading, самому объемному и продолжительному (60 минут), содержится пять текстов, к которым поставлены 45 вопросов. На чтение каждого текста и выполнение относящихся к нему вопросов в среднем отводится 10 минут, так как 10 минут в конце раздела - для переноса ответов в специальную экзаменационную форму.
Следующая особенность раздела Reading - это разнообразие бизнес - тем, собранных в одном тесте, например [7]: Text 1- "Changes in Performance Feedback", Text 2 - "International Teams", Text 3 - "The Effective Leader", Text 4 - Manufacturing Strategy", Text 5 - "Market Research". Это единовременная проверка таких бизнес тем, как Human resources, Organization, Culture, Teambuilding, Leadership, Finance, Product, Marketing. Собрание разных тем в разделе Reading одного теста является неожиданным для студента, имеющего привычку писать тесты по определенной пройденной тематике. Умение мобилизоваться и быстро переключиться с одной темы на другую, также требует тренировки.

Рассмотрим детально содержание первой части международного экзамена BEC Vantage Reading, ее сложности и пути их преодоления.

Текст 1 (250 - 350 слов) - это matching task, для выполнения которого необходимо умение просмотрового чтения для определения главных мыслей и деталей обсуждаемого. Текст разделен на 4 части A,B,C,D (или это могут быть четыре коротких текста, объединенных одной бизнес тематикой) из газет, журналов, брошюр, деловой корреспонденции, книг по Менеджменту. К этим текстам даны 7 утверждений, каждое из которых формулирует идею, содержащуюся в одном из четырех текстов, но выраженную с помощью других лексических единиц, иногда синонимов, а иногда довольно замысловатых формул речи. Таким способом проверяется не только детальное понимание смысла, но и широта профессионального словаря студента.

Подготовкой к выполнению данного задания может стать работа над небольшими текстами, объединенными близкой тематикой, в которых преподаватель учит студентов замечать мелкие нюансы, отраженные в различиях в подаче информации. Следует учить перефразировать, используя синонимы или другие пути выражения данного смысла.

Текст 2 (450 - 550 слов) - это matching task, но иного рода, для выполнения которого необходимо понимание структуры текста и логической последовательности информации. По форме это может быть статья, доклад, отрывок из большого текста, из которого «вынуты» 6 предложений, то есть, в тексте имеются 6 пробелов, которые следует заполнить, выбрав из предложенных семи вариантов (один из предложенных вариантов не имеет отношения к тексту). Традиционно эта часть представляет большую сложность. Во-первых, потому что предполагает наличие большой скорости осмысленного чтения (текст необходимо читать дважды: до подстановки пропущенных предложений и после - для самоконтроля). Во-вторых, в неязыковых вузах не уделяется большое 
внимание обучению структуре текста и его логическому развитию. Поэтому студенту сложно представить лексические и грамматические особенности пропущенных предложений.

Заданием, способствующим развитию необходимых умений, является анализ текстов с ярко выраженной логической последовательностью информации, четким делением на параграфы с помощью слов - связок. Следует обращать внимание, почему предложение подходит или не подходит для подстановки, рассматривать структуру текста как значимый элемент его понимания.

Текст 3 (450 - 550 слов) - это чтение для понимания общего смысла и специальной информации, предоставляемой каждым абзацем. Это может быть деловая пресса, внутренняя документация компании, отрывки из книг по менеджменту. После текста студенту даются шесть вопросов по содержанию прочитанного с тремя опциями ответов на каждый. Студент должен выбрать вариант, соответствующий содержанию текста. Количество абзацев текста часто совпадает с количеством вопросов. Этот вид задания можно назвать традиционным для работы с зарубежными пособиями и не представляет трудности, если сформировано умение читать, понимая смысл.

Умение понимать смысл прочитанного относится к общим проблемам обучения чтению, которые обозначены в начале этой статьи. В начале работы с группой можно рекомендовать читать небольшие тексты, анализируя главную мысль каждого абзаца, определяя его ключевое предложение, а в предложении - ключевое слово. Решающим умением для развития умений реферативной деятельности студента, является умение компрессировать текст. При небольшом словарном запасе, которым обычно владеют студенты неязыковых вузов, умение выделить главное и отбросить второстепенные детали, осложняющие понимание, требует отдельной систематической подготовки. Подготовительная работа для развития умений реферативной деятельности должна ориентировать студента на умение определить: стиль текста и его структуру; главную мысль каждого абзаца текста; главную идею всего текста и сформулировать ее различными по структуре предложениями. Также, считаем важным развитие умения выразить содержание текста количеством предложений, равным количеству абзацев, с постепенным сокращением количества предложений до одного.

Текст 4 (200 - 300 слов) - это проверка знания профессионального словаря и структуры предложения, наиболее часто употребляемой деловой лексики, устоявшиеся и идиоматические выражения. Текст может быть взят из любого источника с доступным содержанием уровня Intermediate, так как это единственное задание, в котором акцент поставлен не на понимании смысла прочитанного, а на умении идентифицировать нужную лексическую единицу для подстановки в определенный пробел. После текста имеются 15 лексических вопросов опций, соответственно количеству пропусков в тексте. К каждому пропуску даны четыре варианта ответов, один из которых правильный.

Сложность данного задания в том, что среди опций находятся слова с близким значением, но только одно из них является верным для употребления в данном контексте или данном устоявшемся выражении. Подготовкой является работа над устоявшимися словосочетаниями из области бизнес корреспонденции и делового общения. Полезным может оказаться ведение специального словаря устойчивых лексических сочетаний.

Текст 5 (150 - 200 слов) - требует умения понимать структуру текста и идентифицировать ошибки, т. е. редактировать текст, путем вычленения лишних слов. Контрольная часть текста расположена на двенадцати пронумерованных строках. На некоторых строках текст не требует коррекции. Задание такого типа часто встречается в зарубежных пособиях, но для студентов оно представляет значительную сложность из-за непонимания структуры предложения.

Полезными окажутся любые задания на нахождение ошибок в тексте. Работа преподавателя во время анализа структуры письменных работ будет способствовать развитию понимания структуры английского языка. Также, работа над текстом задания 5 может быть совмещена с работой над текстом из задания 2, которая так же ориентирована на формирование чувства структуры текста.

\section{Зак^ючение}

Таким образом, даже беглый анализ части Reading как составляющей международного экзамена, дает основания считать, что процесс подготовки к экзамену не только не противоречит целям обучения чтению понимание смысла прочитанного, - но в основном, базируется на умениях, определяющих достижение этих целей. Он дополнительно предоставляет студенту возможность глубже понять структуру английской речи и отработать лексические единицы, составляющие базис деловой коммуникации. Все студенты языкового уровня Intermediate и Upper Intermediate, сдававшие после подготовки пробный экзамен ВЕС Vantage справились с заданиями. Студенты магистратуры, самостоятельно сдавшие экзамен в формате BEC Vantage в специализирующихся на приеме международных экзаменов языковых центрах, показали высокие результаты.

Опыт работы преподавателей и студентов по подго- 
товке к сдаче международного экзамена, с одной стороны, обострил имеющиеся проблемы, с другой, принес позитивные изменения в работу по формированию иноязычной коммуникативной компетенции как инструмента усовершенствования понимания речи, расширения профессионального словаря и самоорганизации во времени. Подготовка студентов-нелингвистов к сдаче международного экзамена реально осуществима в рам- ках обучения на факультетах международного бизнеса, и эта подготовка принесет студентам дополнительные умения и повышение собственной самооценки. Кратко представленные новые международные, социальные и межкультурные реалии обусловили очередной этап совершенствования системы обучения английскому языку в вузах, готовящих специалистов в области международного бизнеса.

\section{ЛИТЕРАТУРА}

1. Bernstein M.M. (2018) Innovative internationalization strategy: how to gain advantageous skills and knowledge to succeed in the global world. / Bernstein M. // Conference Proceedings, International Research Conference "GSOM Emerging Markets Conference - 2018". - St. Petersburg State University Graduate School of Management, - gsom.spbu.ru/emc - October 4-6th, 2018. - pp. 118 - 120.

2. Бернштейн В.Л. Иноязычный компонент в системе высшего профессионального образования. М.: МГЭИ, 2008. 134 с.

3. Savignon S.J. Evaluation of Communicative Competence: the ACTFL Provisional Proficiency Guidelines // Modern Language Journal. - 1985. - Vol.69, - \#2. P. 129 134.

4. Барышников Н.В. Обучение французскому языку в средней школе: вопросы и ответы. - М.: Просвещение, 1992. - 128 с.

5. Scrivener, J. Learning Teaching Third Edition - Heinemann, 2011. $-414 \mathrm{p}$.

6. Бернштейн В.Л. Извлечение информации как главный компонент продуктивного чтения // Интерактивная Наука, - изд-во 000 «Центр научного сотрудничества «Интерактив плюс». 2017 - № 11- С. 28 - 32.

7. Cambridge English: Business Vantage 5 with answers. // University Printing House// Cambridge University Press. - 2019. - 142 p.

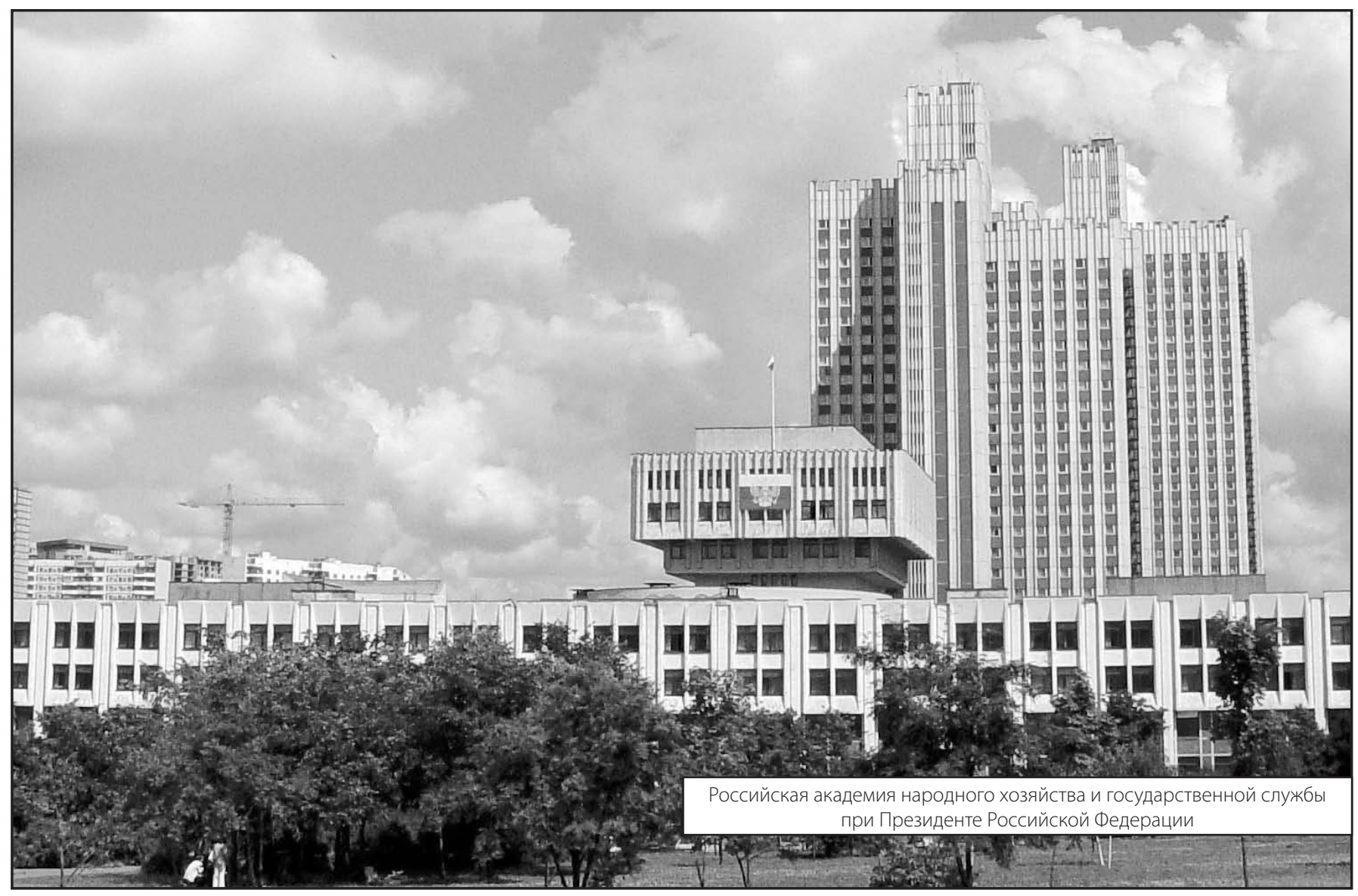

